\title{
BOSQUE DAS MANGUEIRAS: PROJETO PAISAGÍSTICO COMO FERRAMENTA DE REABILITAÇÃO DO ENTORNO DA REITORIA DA UNIVERSIDADE FEDERAL DO PIAUÍ
}

\author{
SILVA, Caio Frederico E \\ Estudante do Curso de Arquitetura e Urbanismo / UFPI. Bolsista de Iniciação Científica CNPQ. \\ E-mail: caiofred@uol.com.br
}

LOPES, Wilza Gomes Reis

Arquiteta, Professora Doutora do Departamento de Construção Civil e Arquitetura/Centro de Tecnologia da UFPI. E-mail: izalopes@uol.com.br

\section{MATOS, Karenina Cardoso}

Arquiteta, Professora Mestre do Departamento de Construção Civil e Arquitetura/Centro de Tecnologia da UFPI. E-mail: karenina@ufpi.br

\section{RESUMO}

O projeto de reabilitação do "Bosque das Mangueiras" da Reitoria da Universidade Federal do Piauí - UFPI foi desenvolvido como experiência piloto do grupo de estudos do Laboratório Urbano da Paisagem - LUPA e apresenta diagnóstico e pressupostos teóricos para subsidiar intervenções paisagísticas nos espaços livres do campus universitário. Considerando a valorização das áreas verdes e a avaliação bioclimática, integrou-se a este trabalho o projeto de iniciação científica, em andamento, que caracteriza o perfil microclimático da cidade universitária identificando neste espaço livre bons condicionantes de conforto ambiental. A reabilitação do bosque agregará valores ao entorno, proporcionando experiências de contemplação, permanência e contribuindo na legibilidade da Reitoria, símbolo de representatividade.

\section{Palavras-chave: Reabilitação, paisagem, legibilidade.}

\section{Introdução}

O "Bosque das Mangueiras", área verde localizada próximo ao bloco da administração superior - a Reitoria da UFPI - é, hoje, pouco valorizado e pouco percebido como elemento importante na composição ambiental do campus. Juntamente com a reitoria, apresentam a necessidade de um olhar mais apurado, onde o diagnóstico e a proposta são ferramentas utilizadas para tal valorização das áreas verdes que, conforme avaliação bioclimática, têm importante contribuição quanto ao conforto térmico, que é fundamental para a garantia da agradabilidade nos espaços livres.

O clima da cidade de Teresina é conhecido por apresentar elevados índices de temperatura, contribuindo para o desconforto térmico do local. O estudo de Lima e Assunção (2002) na cidade de Teresina apresentou a temperatura média do ar de $27,3^{\circ} \mathrm{C}$, e temperaturas médias máxima e mínima, respectivamente, de $33,5^{\circ} \mathrm{C}$ e de $22,2^{\circ} \mathrm{C}$. Logo, os espaços livres e verdes contribuem significativamente para a melhoria das condições ambientais do campus.

Castelo Branco (2003) afirma que a alteração do revestimento do solo, a redução da cobertura vegetal, o aumento de superfícies refletoras, o tráfego de veículos e atividades geradoras de calor, decorrentes do processo de urbanização provocam elevação na temperatura do ar. Em Teresina, onde atualmente $94,7 \%$ da população do município residem na área urbana, deve-se ter na amenização do clima um fator preponderante no seu planejamento. 
Para Mascaró et al. (2000), o uso da vegetação é um recurso eficiente contra o calor nas cidades tropicais úmidas, pois, além de fornecer sombreamento, permite a passagem da brisa local e absorve de maneira eficaz a radiação térmica de onda longa sobre as folhas refrescadas pela evaporação. A arborização substitui com vantagens qualquer sistema de sombreamento, inclusive nos climas úmidos, atuando nos microclimas urbanos, contribuindo para o controle da radiação solar, da temperatura e da umidade do ar, da ação dos ventos e da chuva e também serve para amenizar a polvição do ar e, em determinadas situações, a polvição sonora.

De acordo com Bartalini (1986), a temperatura das áreas cobertas por vegetação é sensivelmente menor que as das áreas nuas ou edificadas, essas áreas possuem variações térmicas que podem contribuir na ventilação da cidade. Assim, a arborização urbana pode atenuar os efeitos das "ilhas de calor", que tendem a se formar sobre o espaço urbano influindo nas condições climáticas.

Criado em 1971, o campus Ministro Petrônio Portella da Universidade Federal do Piauí está localizado na zona Leste da cidade de Teresina, encontrando-se ainda em expansão, com aumento de seu espaço construído. Os espaços livres têm valor paisagístico e bioclimático, logo, estudos sobre essas áreas com potencialidade climática e paisagística são importantes estratégias para a manutenção dos cenários urbanos do campus e com isso uma cultura de identidade com a cidade universitária.

Na implantação do campus, as espécies nativas não foram mantidas, no entanto foram realizados plantios de outras espécies em todas as áreas livres, porém, espécies exóticas, que não se identificavam com as paisagens da cidade de Teresina. Como alternativa sustentável e telúrica, os estudantes do Diretório Central dos Estudantes no ano de 1979, propuseram, para o então reitor professor José Camilo Silveira Filho, que todas as espécies arbóreas do campus fossem substituídas por mangueiras e cajueiros, árvores frutíferas tipicamente piauienses. Segundo o professor e historiador Fonseca Neto, atual diretor do Centro de Ciências Humanas e Letras, no contexto da época, enquanto membro do DCE, o plantio das mangueiras, que hoje formam o bosque da reitoria, foi uma conquista dos estudantes na busca por um local mais agradável, que representasse simbolicamente a importância das áreas verdes para as cidades, em especial para a cidade de Teresina (informação verbal) ${ }^{a}$.

Entende-se a cidade universitária como um exemplo que também segue a dialética de diálogo entre seus espaços, suas tradições e o envolvimento harmonioso com sua população. Partindo do pressuposto de que a harmonia entre o ambiente natural, a paisagem construída e a comunidade acadêmica são fundamentais para a busca de identidade local e para a manutenção da integridade do nosso meio, a comunidade da cidade universitária da UFPI busca reabilitar seus espaços livres. Estes estão subutilizados e, muitas vezes, formam paisagens de pouca legibilidade, como é o caso do bloco da Reitoria, que hoje não se integra ao bosque de mangueiras, objeto de estudo deste trabalho.

É senso comum associar-se a imagem das universidades com a imagem de suas reitorias, que por sua vez, estão associadas ao valor simbólico de poder e representatividade. E para isso, torna-se necessária que sua localização no interior do campus seja estratégica ou de fácil legibilidade para a comunidade acadêmica. Esse é um dos objetivos perseguidos com o projeto paisagístico do bosque. A intenção é otimizar as áreas agradáveis do campus através da reabilitação do "Bosque das mangueiras".

310 objetivo deste trabalho foi o de apresentar um diagnóstico e os pressupostos teóricos que subsidiaram o projeto de intervenção paisagística no espaço do "Bosque das Mangueiras" da Universidade Federal do Piauí - UFPI, campus Ministro Petrônio Portella, da localizado na zona leste da cidade de Teresina. 


\section{Metodologia}

Partindo-se do pressuposto da importância da paisagem, da imagem, da legibilidade e das relações de harmonia entre o objeto e o observador foram escolhidos os conceitos dos autores Lynch (1997) e Cullen (1983) como referenciais teóricos para o desenvolvimento da pesquisa.

A pesquisa foi desenvolvida em cinco momentos:

$1^{\circ}$ momento: discussão acerca do tema e sua relação com a área de estudo; quando foram identificados: a pouca legibilidade do bloco da Reitoria e a falta de integração com o "Bosque das Mangueiras"; a potencialidade do bosque como espaço livre - público de contemplação, permanência e potencial elemento para valorização do prédio da reitoria;

$2^{\circ}$ momento: foram realizadas medições de temperatura, umidade do ar e velocidade dos ventos no bosque das mangueiras, nos horários de $09 \mathrm{~h} 00 \mathrm{~min}, 15 \mathrm{~h} 00 \mathrm{~min}$ e $21 \mathrm{~h} 00 \mathrm{~min}$, alcançando os três turnos diários, em três dias consecutivos, durante os meses de outubro, novembro e dezembro de 2005, janeiro e fevereiro de 2006. Para a coleta de dados foram usados os seguintes aparelhos:

- Higrômetro e Termômetro (INSTRUTHERM HT 156)

- Anemômetro (Lambrecht METEO DIGIT I)

$3^{\circ}$ momento: entrevista informal com o reitor da UFPI, funcionários da reitoria, professores e alunos do campus; visitas "in loco", levantamento fotográfico do local e da arborização existente no bosque.

$4^{\circ}$ momento: diagnóstico da área de estudo através de dados primários e secundários.

Esses elementos trouxeram decisões projetuais com a observação das linhas de desejo existentes do local e problemas de infraestrutura que o bosque possui.

$5^{\circ}$ momento: elaboração do estudo preliminar, tomada de decisões a partir dos referenciais teóricos e análise do local em estudo.

O estudo de percepção e projeto foi elaborado pelo Laboratório Urbano da Paisagem - LUPA, vinculado ao Departamento de Construção Civil e Arquitetura. O laboratório é coordenado pelas professoras Wilza Gomes Reis Lopes e Karenina Cardoso Matos e na realização deste contou com a colaboração dos alunos de Arquitetura e Urbanismo: Emanuella Camarço, Renata Castilho, Marta Raquel Alves e Caio Frederico e Silva.

\section{Percepção da paisagem}

\subsection{Inter-relação entre os usuários e o meio ambiente}

Em seu estudo sobre os espaços livres urbanos, Matos (2004b). mostra que a cidade deve ser considerada como um lugar de encontro entre o ambiente natural, a paisagem construída e seus habitantes, envolvidos harmoniosamente. Tornando-se assim um ambiente poético e simbólico que mostra suas complexidades, tradições históricas, uma obra de arte e não apenas um artefato para atender às suas necessidades funcionais.

Para Araújo e Caran (2004), o grande desafio das cidades é o crescimento e desenvolvimento urbano que proporcionem geração de riqueza, qualidade de vida e qualidade ambiental para seus atuais e futuros habitantes. Esse é o princípio do desenvolvimento sustentável, o qual estabelece o meio ambiente como ponto comum e de equilíbrio entre a tecnologia e o progresso no espaço urbano.

E é nesse espaço onde todas as trocas acontecem, sobretudo num ambiente acadêmico de produção de conhecimento científico e que o contato com o meio natural torna-se elemento facilitador da vivência e troca de experiências. 
Segundo Tuan (1980), na vida moderna, o contato físico com o próprio meio ambiente é cada vez mais indireto e limitado a ocasiões especiais. Fora da decrescente população rural, o envolvimento do homem tecnológico com a natureza é mais recreacional do que vocacional. Este contato com a natureza deve ser estimulado através de elementos da paisagem que transmitam sentimento de identidade com o habitante. A palavra topofilia é um neologismo criado por Tuan (1980) que representa exatamente este elo afetivo entre o homem e o meio ambiente.

Ao se formular políticas de intervenções urbanas, é preciso preservar o ambiente natural e construído, visando à geração ou manutenção do bem-estar e da qualidade de vida dos habitantes da cidade, que possuem instintivamente este afeto com os cenários da paisagem percebida.

Segundo Matos (2004a, p.16), "É necessário (re)aproximar o sujeito ao que ele produz, dos elementos construídos e simbólicos - dos quais ele faz parte, pois o sujeito não pode operar/viver fora deles; os sujeitos fazem parte do meio, são eles que os conhecem, vivenciam e criam elos afetivos aos lugares, criando, assim, a identidade de cada lugar".

Neste sentindo propõe-se que esta relação seja cada vez mais intensa e poética. No entanto as questões ambientais são fundamentais para a identificação de locais agradáveis para o usufruto do homem.

A procura por espaços aprazíveis torna-se constante, no campus da Universidade Federal do Piauí, mas os grandes espaços livres ao tempo em que permitem o contato com a natureza não proporcionam a permanência dos usuários nesses espaços e a adequação dessas áreas às demandas atuais favorece.

A partir do levantamento de dados no local, em pesquisa em andamento, realizada pelos autores, foi constatado que o bosque das mangueiras apresenta potencialidades climáticas diferenciadas das outras áreas livres do campus, apresentando índices de conforto térmico agradáveis em todas as horas do dia.

Observou-se que, em relação à temperatura e, o referido espaço foi o que apresentou o menor valor, com média de $33,48^{\circ} \mathrm{C}$. Com referência à umidade de ar, foi o espaço da reitoria que apresentou, também, o melhor índice, com a maior umidade, no valor de 60,26\%. Neste local existem aproximadamente 100 (cem) mangueiras, que possuem cerca de 25 anos de idade, e todas as árvores são localizadas em piso permeável de terra, que garantem um microclima bastante confortável em todos os momentos do dia.

\subsection{A percepção do espaço}

partido arquitetônico para os primeiros riscos projetuais do bosque foi a permanência do bosque verde, que é o cenário atual percebido por todos os usuários do campus. Dessa forma, essa imagem não poderia ser modificada tendo em vista que é também objetivo deste trabalho a busca pela identidade do campus.

A diretriz da manutenção da paisagem atual faria o papel poético da relação homem-meio ambiente, e ainda os caminhos por entre as sombras agradáveis das mangueiras permitiriam a relação intensa, provocadora, onde os andarilhos são levados pelas curvas das linhas de desejo a harmonizarem-se ao contexto natural, integrando-se ao conjunto e compondo a nova paisagem modificada.

Outros elementos contribuirão para a reabilitação do bosque. Os caminhos, citados acima 312 cumprem a principal funcionalidade do bosque levando a comunidade acadêmica, ora a chegar a reitoria, ora (a maioria das vezes) a passar pelo bosque, sentindo-o, e seguindo seu percurso em direção aos demais centros de ensino que são localizados do outro lado do bloco da administração superior. 
Os elementos configurados do espaço permitem ao observador uma sensação de segurança, afirma Lynch (1997), pois precisamos "de um ambiente que não seja simplesmente organizado, mas também poético e simbólico". A legibilidade é um dos principais indicadores da boa imagem da cidade e conseqüentemente da valorização das suas áreas verdes e seu entorno.

As áreas verdes são consideradas neste trabalho como o elemento visual e paisagístico que permite e facilita a leitura da cidade universitária. Neste contexto o bosque representa um ponto nodal, que conceituado por Lynch (1997, p. 52), representam "[...] lugares estratégicos de uma cidade, através dos quais o observador pode entrar, são os focos intensivos para os quais ou a partir dos quais ele se locomove." Na medida em que o bosque marca visualmente o local da reitoria dentro do campus, tornando-se assim elemento de comunicação urbana e atrator de outros elementos simbólicos, construídos e naturais."

\subsection{Espaço urbano-poético-identidade}

Cullen (1983) mostra em seus estudos que abrigo, sombra, conveniência e um ambiente aprazível são as causas mais freqüentes da apropriação de espaço, as condições que levam à ocupação de determinados locais.

Ainda segundo Cullen (1983), a inserção de equipamentos urbanos no espaço público pode contribuir para que se entenda os tipos de ocupação daquele espaço e criar um meio-ambiente que não seja fluído e monótono, mas sim estático e equipado, conferindo ao espaço caráter mais humano e diverso.

Segundo Cullen (1983), a criação de recintos ${ }^{b}$ é fundamental para possibilitar a permanência das pessoas no espaço a que se propõe essa convivência saudável, a troca de experiências, ora do homem ou seu semelhante ora deste com a natureza que o cerca.

Dentro da concepção de recinto, numa solução lúdica e metafórica de criar um estar central (um marco dentro do marco) foi desenvolvido o projeto de uma pérgula com troncos de carnaubeira, planta típica das chapadas de cerrados do estado do Piauí, compondo formato alusivo a logomarca da Instituição UFPI.

Os caminhos do bosque têm traçados ondulados. Essa ondulaçãoc, leva poeticamente os transeuntes por entre as sombras das copas das árvores. As formas curvilíneas, seguindo concordâncias, foram preferidas para esse espaço pois a pretensão dos projetistas é a criação de caminhas naturais, que levam os passos dos usuários por um bosque penetrável e as linhas soltas e onduladas favorecem esse contato mais sensível.

Esses caminhos precisam ser bem pavimentados para garantir segurança aos caminhantes, no entanto esse revestimento não precisa ser rígido. A pavimentação deve ser adotada de forma cuidadosa, dosando-se as necessidades para que o local não perca as características originais de área muito permeável.

Entre os diversos elementos naturais que compõem a paisagem urbana, a árvore é, sem dúvida, o mais freqüente, e a relação entre árvores e cidades tem uma longa e respeitável tradição.

\section{A reabilitação do Bosque das Mangueiras}

\subsection{Situação atual e situação proposta}

Partindo do pressuposto da necessidade da valorização dos espaços livres do campus e da pouca legibilidade da reitoria, a proposta de reabilitação do bosque das mangueiras tem como objetivo principal a discussão acerca da importância desses espaços para a cidade de Teresina e, em especial, para o campus da UFPI, a fim de descortiná-los não só como um potencial es- 
paço visual, mas também, de permanência e valorização da paisagem do seu entorno (figuras 1 e 2).

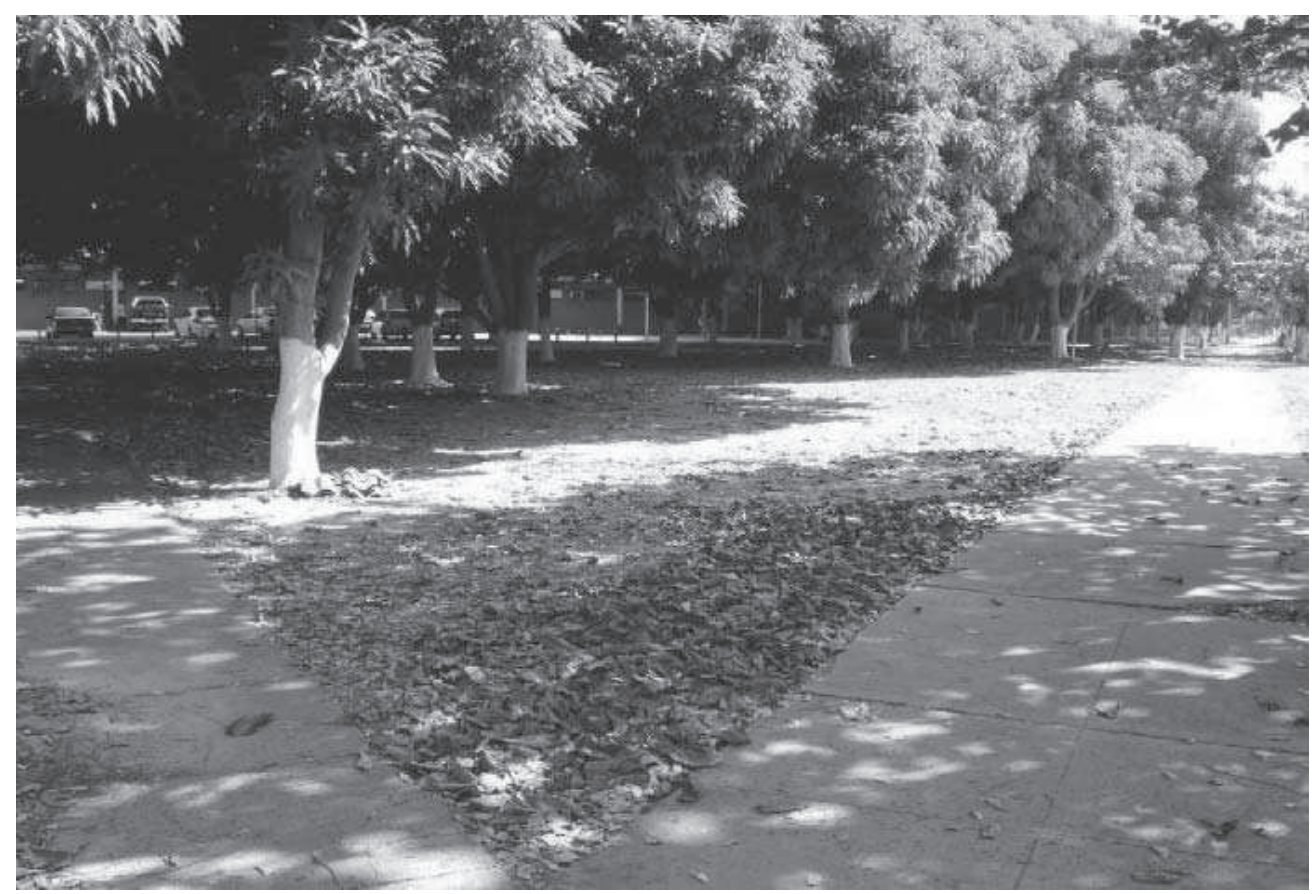

Figura 1: Acessos não-utilizados Fonte: LUPA, 2005

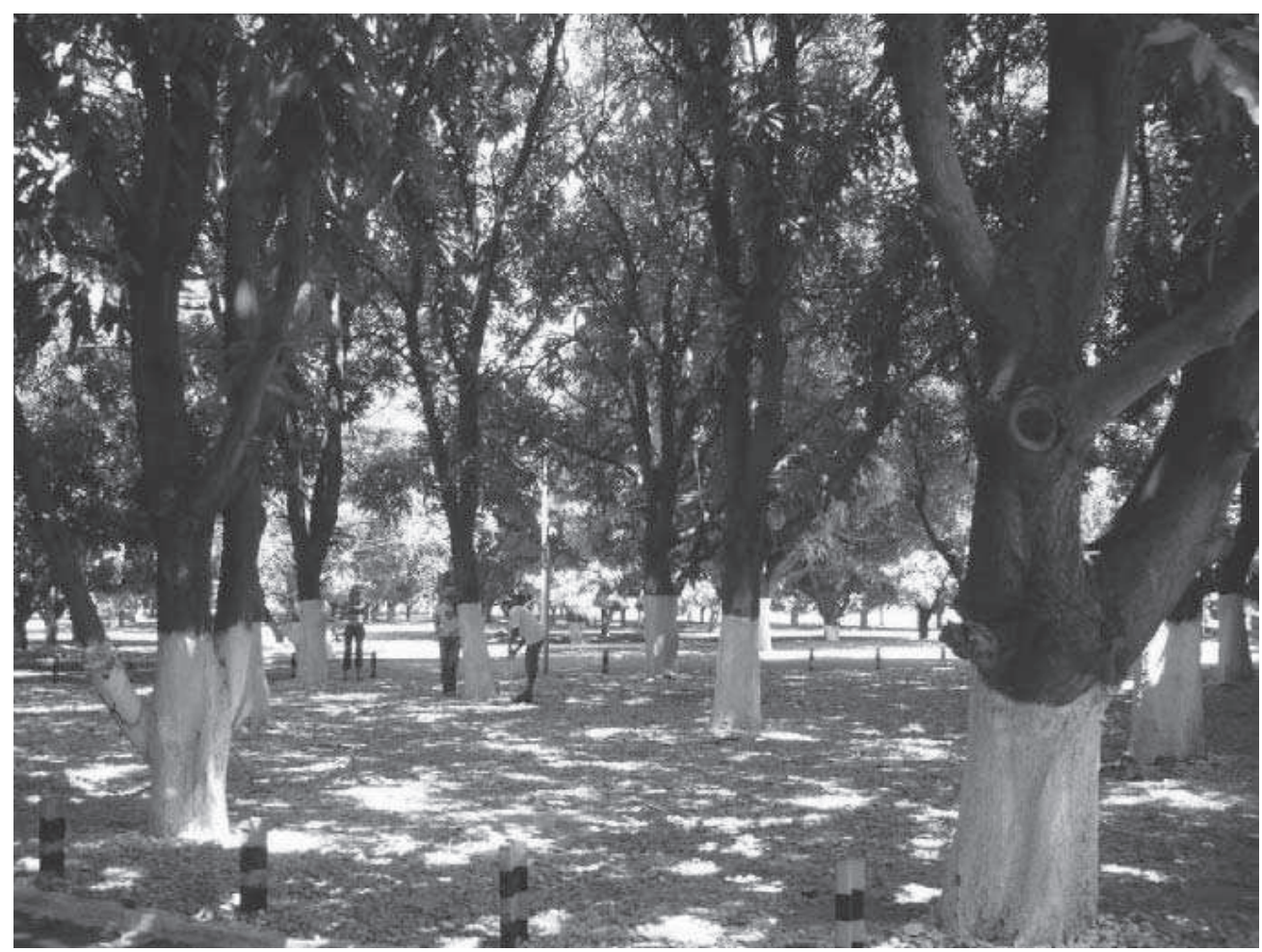

Figura 2: As sombras do bosque

Fonte: LUPA, 2005 


\subsection{Resultados esperados com a proposta}

- A reabilitação do bosque agregará valor ao entorno: Reitoria, melhorando sua imagem perante a comunidade acadêmica e tornando-se um marco urbano e facilitando assim a localização do respectivo prédio. (Figuras 03, 04 e 05)

- O bosque passará a ser identificado como um elemento nodal dentro da reitoria.

- Os usuários vão perceber a qualidade visual, de conforto ambiental e utilitário dos espaços livres.

- Discussão acerca da importância de estudos sobre a paisagem para a UFPI e para a cidade de Teresina.

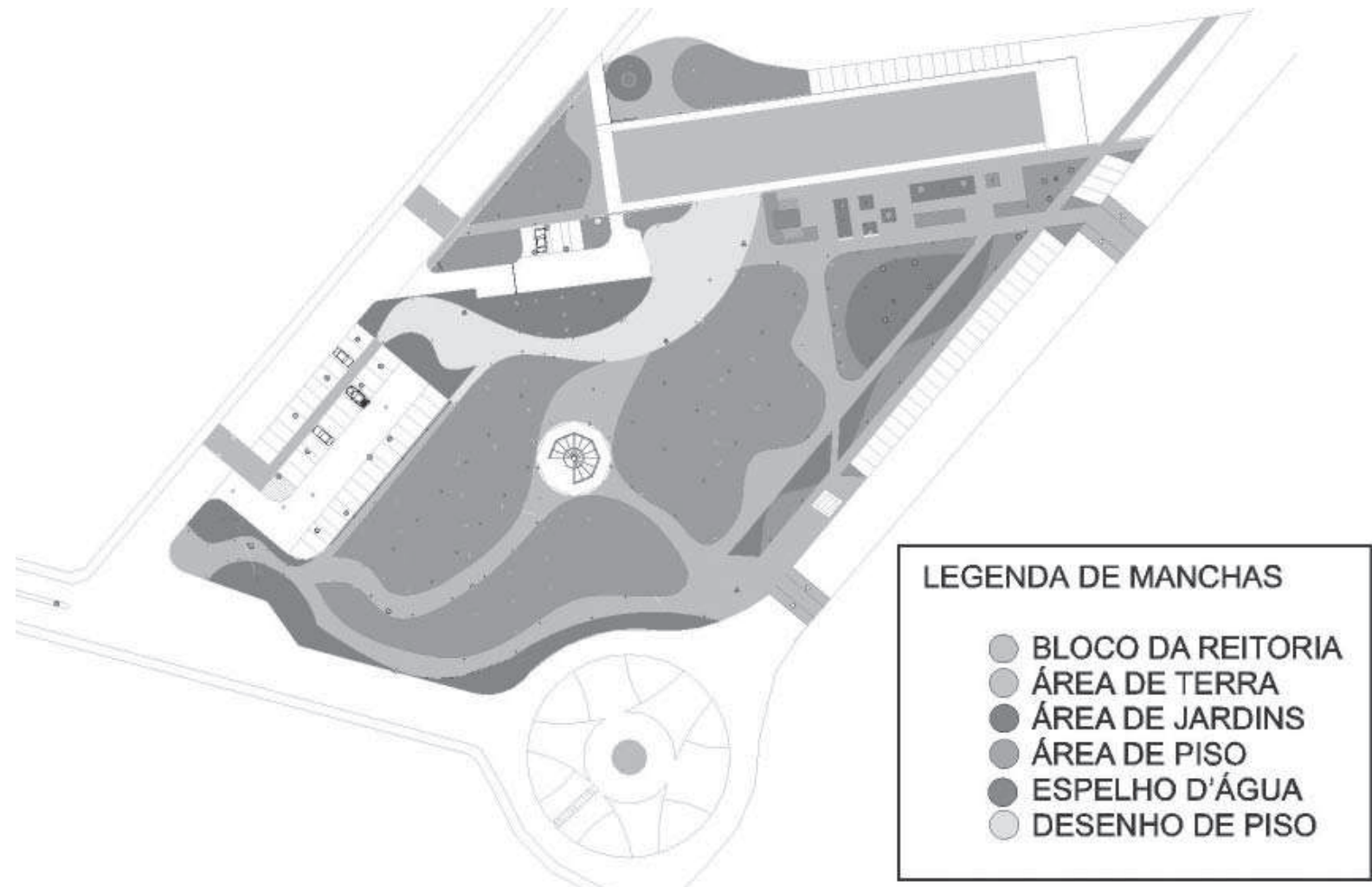

Figura 3: Estudo Preliminar do Projeto Paisagístico Fonte: LUPA, 2005

Foi proposta ainda a mudança dos materiais, hoje empregados nos pisos que se encontram em péssimo estado de conservação, por materiais mais duráveis e de mais fácil manutenção.

Serão colocados equipamentos urbanos como bancos, lixeiras e telefones públicos no sentido de possibilitar uma maior permanência dos usuários. A acessibilidade é conseguida no projeto através de acesso com rampas a partir de todas as vias de tráfego que chegam ao bosque.

Considerando-se a realização plena do projeto proposto, além dos valores subjetivos esclarecidos no decorrer deste trabalho, busca-se uma maior segurança do campus, com o uso de iluminação artificial para a região estudada, a poda planejada das árvores garantiria a circulação das correntes de ventos e a presença de iluminação natural durante o dia. 


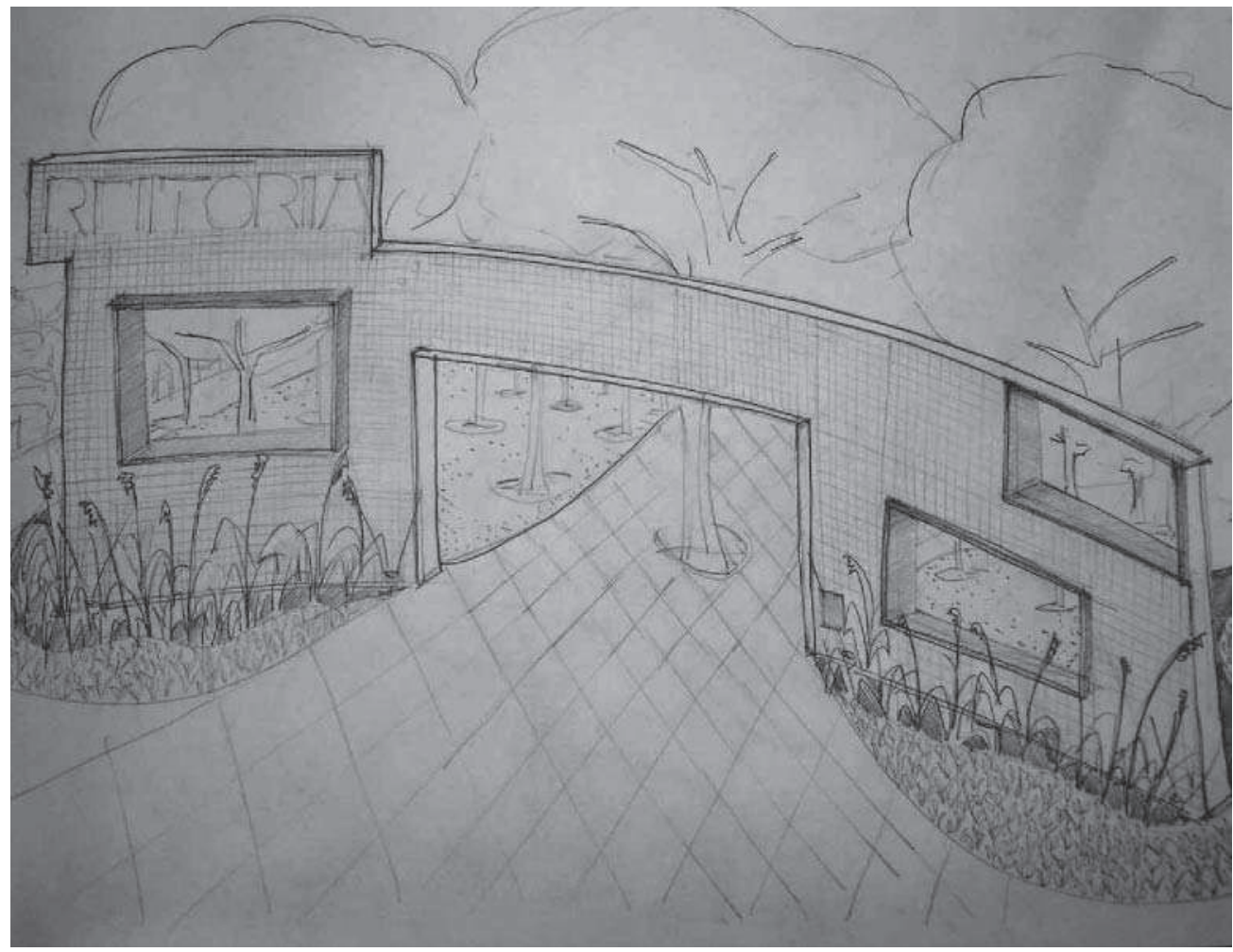

Figura 4: Desenho esquemático (proposta) - portal do bosque, marco visual do conjunto paisagístico Fonte: LUPA, 2005

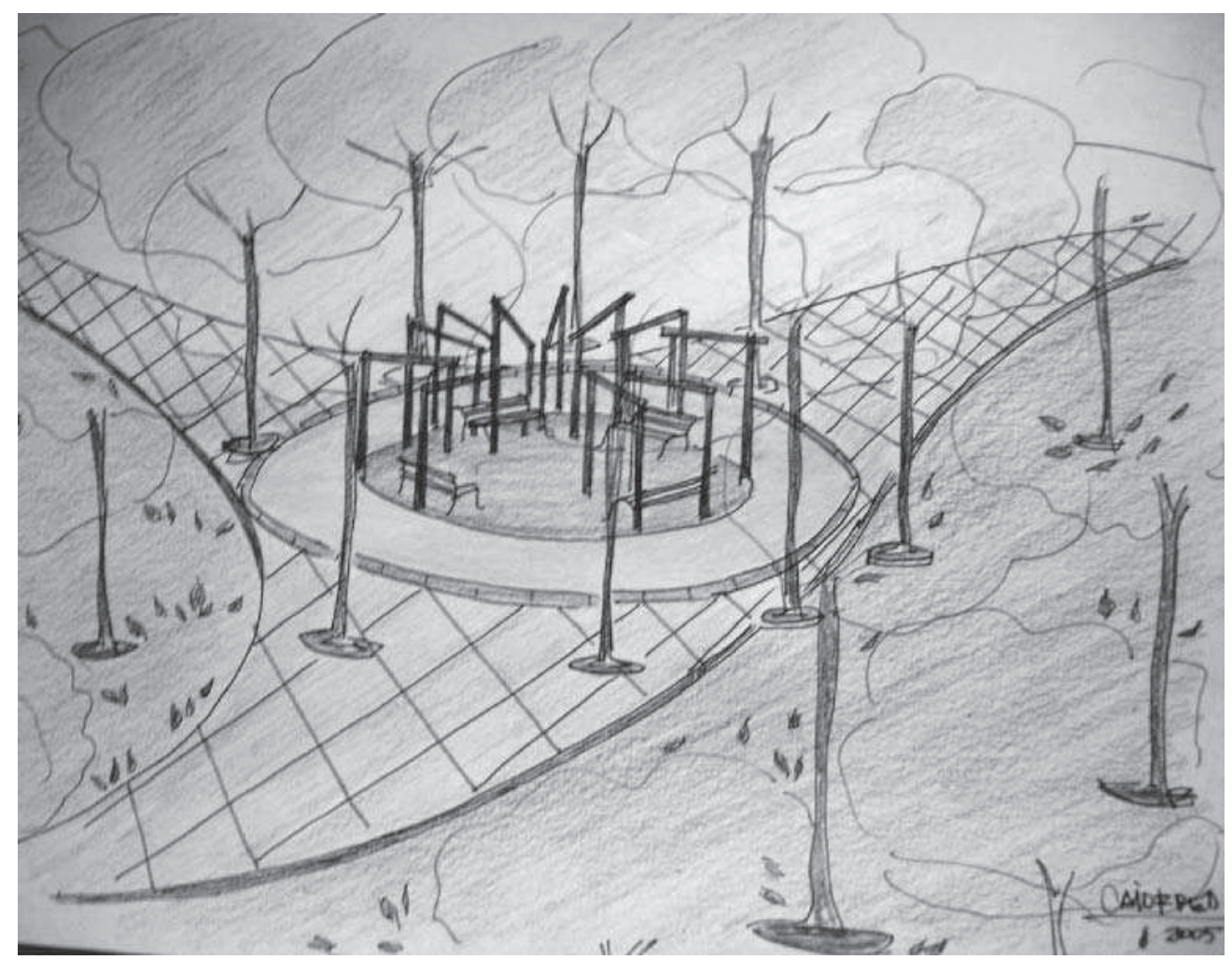

Figura 5: Desenho esquemático (proposta) - pérgolas de Carnaubeira criarão recinto no centro do bosque, no encontro dos caminhos Fonte: LUPA, 2005 


\section{Considerações finais}

Em Teresina os espaços agradáveis são necessários e faltam projetos de intervenção que possibilitem o uso desses espaços. A mesma observação aplica-se ao campus universitário da UFPI.

Hoje, a presença de marcos urbanos, como elementos de comunicação urbana são muito escassos tornando o campus muito pouco legível. A reabilitação do bosque agregará valor ao entorno: Reitoria, melhorando sua imagem perante a comunidade acadêmica e tornando-se um marco urbano do campus que é outro grande objetivo a ser atingido com a execução do "Bosque das Mangueiras".

Com essas diretrizes, em conjunto com toda a percepção dos espaços livres e sua singular importância no contexto da cidade universitária, os usuários vão perceber a qualidade visual e utilitária dos espaços livres, passando a utilizar

mais esses espaços, e dessa forma, evitando seu abandono e cultivando sua identidade com o lugar.

\section{Notas}

(1) Informação verbal, obtida por meio de contato pessoal com o Professor Antônio Fonseca dos Santos Neto, que vivenciou o processo de plantio das mangueiras no referido período.

(2) Recinto é a unidade base duma certa morfologia urbana. Fora dele, o ruído e o ritmo apressado da comunicação impessoal, vai-vem que não se sabe para onde vai nem donde vem; no interior, o sossego e a tranqüilidade de sentir que o largo, a praceta, ou o pátio têm escala humana. O recinto é o objetivo da circulação, o local para onde o tráfego nos conduz. Sem ele, o tráfego torna-se absurdo (CULLEN, 1983).

(3) Ondulação não é apenas uma linha sinuosa e sem objetivo, mas sim o desvio obrigatório a um eixo ou norma invisíveis, com vista a proporcionar o prazer de coisas tão elementares e vitais como luz e sombra (o contrário da monocromia), ou proximidade e distância (o oposto do paralelismo) e como a leve agitação da folhagem ao sabor de uma brisa suave ou como um mesmo pensamento expresso de várias maneiras diferentes (CULLEN, 1983).

\section{Bibliografia}

ARAÚJO, Bianca Carla Dantas de; CARAN, Rosana. Análise ambiental: Estudo bioclimático urbano em centro histórico. In: ENCONTRO DA ASSOCIAÇÃO NACIONAL DE PÓS-GRADUAÇÃO E PESQUISA EM AMBIENTE E SOCIEDADE, 2., 2004, Indaiatuba-SP, Anais... Campinas: ANPPAS, 2004.

BARTALINI, V. Áreas verdes e espaços livres urbanos. Paisagem e Ambiente: Ensaios. São Paulo: Edusp, n. 1 e 2, p. 49-54, 1986.

CASTELO BRANCO, Aline Elvas. Urbanização e clima em Teresina. Cadernos de Teresina. Teresina, n. 35, p.10-15, 2003.

CULLEN, Gordon. Paisagem urbana. Lisboa: Edições 70, 1983.

DEL RIO, Vicente. Cidade da mente, cidade real: Percepção ambiental e revitalização na área portuária do RJ. In: DEL RIO, Vicente. Percepção ambiental: A experiência brasileira. 2 ed. São Paulo: Studio. Nobel, 1999.

LIMA, M. G de.; ASSUNÇÃO, H. F. da. Estimativa da temperatura do ar no Piauí. Teresina: UFPI, 2002.

LYNCH, Kelvin. A imagem da cidade. São Paulo: Martins Fontes, 1997.

MASCARÓ, Juan Luis; MASCARÓ, Lúcia; SOUTO, Ana Elisa; SKOWRONSKI, Aline; SOUZA, Luciana Rosa de; LOPES, Vivian P. Chanas. Arborização urbana: Aspectos ambientais, energéticos e de harmonia com a infra-estrutura urbana. In: ENCONTRO NACIONAL DE PAISAGISMO EM ESCOLAS DE ARQUITETURA E URBANISMO NO BRASIL, 2000. Rio de Janeiro. Anais... Rio de Janeiro: FAUUFRJ, n. 1, 2000, 1 CD-ROM.

MATOS, Karenina Cardoso. A paisagem das águas: A percepção dos usuários como subsídios para elaboração de diretrizes urbanísticas para as margens dos rios Poti e Parnaíba e seu entorno (Teresina-PI). 2004. Dissertação (Mestrado em Arquitetura e Urbanismo) - UFRN, Natal, 2004. 
MATOS, Karenina Cardoso. A Praça Marechal Deodoro da Fonseca como espaço livre público de Teresina-PI. In: NÚCLEO DE PESQUISA EM TECNOLOGIA EM ARQUITETURA E URBANISMO - NUTAU, 2004, São Paulo. Anais... São Paulo: FAUUSP, 2004, 1CD-ROM.

TUAN, Ti-Fu. Topofilia. Um estudo da percepção, atitudes e valores do meio ambiente. São Paulo, 1980.

Agradecimentos: Nossos agradecimentos ao Conselho Nacional de Desenvolvimento Científico e Tecnológico - CNPq, pela concessão de bolsa de iniciação científica. 